\title{
LOS PODERES DE EMERGENCIA EN URUGUAY
}

\section{Rubén FLORES DAPKEVICIUS*}

RESUMEN: El presente trabajo refiere las situaciones que pueden determinar la adopción de poderes de emergencia, por ello sucintamente presentamos los conceptos fundamentales que presentan al Estado de derecho como orden jurídico, los derechos humanos y sus garantías, para luego ingresar de lleno al análisis del tema en la República Oriental del Uruguay. Los poderes de emergencia son instrumentos de derecho constitucional que intentan salvar el Estado de derecho cuando existen circunstancias excepcionales que lo atacan. En ese sentido, el estado de sitio y la ley marcial son ejemplos clásicos. Su regulación precisa y taxativa en la Constitución es una garantía procedimental fundamental. La suspensión de determinados derechos humanos exige esa regulación en detalle.

Palabras clave: estado de derecho, orden jurídico, poderes de emergencia, estado de sitio, suspensión de derechos humanos.
ABSTRACT: This paper refers to situations determining the adoption of emergency powers so we submit succinctly the fundamental concepts that relate to the rule of law as legal order, human rights and its guarantees, then, we enter fully analyzing the subject on the Oriental Republic of Uruguay. The emergency powers are instruments of constitutional law in order to protect the rule of law when exceptional circumstances are attacking it. State of siege and martial law are classic examples. Their precise and limited constitutional regulation is a fundamental procedural guarantee. The suspension of certain human rights requires such a regulation in detail.

Descriptors: rule of law, legal order, emergency powers, state of siege, human rights suspension.

* Doctor en derecho y ciencias sociales por la Universidad Mayor de la Republica; profesor de Derecho constitucional y administrativo de la Universidad de la República Oriental del Uruguay; profesor del Master de Derecho Administrativo Económico de la Universidad de Montevideo.

Fecha de recepción: 24 de marzo de 2008.

Fecha de dictamen: 2 de julio de 2008. 


\section{EL ESTADO DE DERECHO}

\section{Concepto}

Estado de derecho es aquel orden jurídico que se caracteriza por la sujeción del Estado y su administración a la ley y el respeto de los derechos subjetivos de los individuos, que son prevalentes al poder público en el supuesto de duda. Se opone al Estado de policía o absolutista. De esta forma el Estado, en sus relaciones con sus habitantes y para la garantía de su estatuto individual se somete, por su propia legislación al derecho. Esta premisa es el cimiento fundamental del orden jurídico democrático constitucional que regula la convivencia de los hombres. ${ }^{1}$

\section{Caracteres}

De la definición propuesta pueden extraerse las siguientes consecuencias que caracterizan al Estado de derecho:

a) El Estado, en un Estado de derecho, está sometido al orden jurídico.

b) La consagración o reconocimiento de los derechos fundamentales, prevalentes, y la previsión de sus garantías son para protegerlos. Esas características nos permiten distinguir el Estado de derecho formal, transpersonalista, del Estado de derecho material personalista. El Estado de derecho formal, transpersonalista, es aquel donde se sigue la forma de ejecución de la norma superior para crear un orden jurídico donde prevalece el Estado sobre el individuo al que no se le respetan sus derechos subjetivos. El ejemplo típico es el Estado nacional socialista alemán. El Estado de derecho material personalista es aquel donde prevalecen los derechos humanos y el principio de libertad. Ante la duda siempre debe estarse por la libertad y los derechos del ser humano. Esta distinción es de singular importancia para entender los poderes de emergencia y la problemática que enfrentamos los publicistas cuando analizamos las situaciones extremas que autorizan su adopción. ${ }^{2}$

1 Flores Dapkevicius, Rubén, Manual de derecho público, Buenos Aires, Euros Editores, 2007, t. I, p. 199.

2 Obsérvese la importancia de los estados de emergencia y su utilización inadecuada, lo que amerita lo discutido del tema, por los posibles abusos del Poder Ejecutivo. En la Alemania nazi se produjo la excepción que desembocó en el caos. Ello aconteció luego del incendio que destruyó el edificio del Reichstag en 1933. Se culpó a los comunistas y 
c) Un sistema de controles entre los órganos estatales, y del pueblo mediante diversos instrumentos, por ejemplo, todos son institutos de democracia directa.

d) Consagración plena del principio de separación o de coordinación del poder en las hipótesis extremas. Recordamos que fue el artículo 30 de la Constitución de Massachussetts de 1780 la que establece, por vez primera, el principio. "En el gobierno de esta comunidad el sector legislativo nunca ejercerá los poderes Ejecutivo y Judicial o cualquiera de ellos..." y así para cada uno de los poderes estatales.

e) La responsabilidad del Estado por sus actos o hechos que surjan del ejercicio de todas las funciones jurídicas que el derecho le atribuye para desarrollar sus cometidos, incluidos los poderes de emergencia.

\section{LOS DERECHOS HUMANOS Y SUS GARANTÍAS}

\section{Concepto de derechos humanos}

La presentación del tema corresponde porque, en el supuesto de los poderes de emergencia podrán acontecer situaciones que violen los derechos humanos o, dentro de la normativa, los restrinjan. Observaremos también las garantías que podrían ser limitadas en el supuesto de excepcionalidad institucional

Los derechos humanos son el conjunto de derechos de que gozan las personas y que no pueden ser restringidos, salvo, excepciones extremas, ni violados, esencialmente, por los gobernantes.

\section{Garantías}

Hemos definido los derechos humanos. Ahora bien ¿cuál es la forma para que esos derechos sean efectivamente respetados?

La pregunta nos conduce a la distinción entre derechos y garantías.

los nazis emitieron dos decretos de emergencia en los que se otorgaban poderes casi ilimitados a Hitler. Tras estos acontecimientos, los nazis y sus aliados nacionalistas obtuvieron la mayoría por un estrecho margen de votos y no tuvieron ninguna dificultad en conseguir la aprobación parlamentaria de la Ley de Autorización de marzo de 1933 que confirmaba sus poderes dictatoriales. El resto es historia bien conocida. 
El ser humano, por ser tal, tiene determinados derechos que son anteriores a su reconocimiento por el Estado, siendo un fin en sí mismo. Por ello el Estado de derecho debe ser entendido en su sentido material y personalista, negando la categoría a las concepciones transpersonalistas. Esos derechos son los que conocemos como derecho a la vida, seguridad, honor, dignidad, trabajo, propiedad, etcétera.

Para su consolidación y defensa se establecen determinados medios. Estos instrumentos son los que podemos englobar en el término garantías.

La garantía, entonces, protege el derecho en el sentido que lo afirma y consolida, lo hace visible y tangible para el resto de la humanidad que observa su desenvolvimiento, también, en su defensa. Hace, en definitiva, que el reconocimiento de los derechos no sea una mera declaración de principios. Esos instrumentos no deberían limitarse, en su ejercicio, como se hace con los derechos, en virtud del respeto del derecho de los demás o de la colectividad, por ejemplo el derecho de propiedad. Esa imposibilidad de limitación del ejercicio de la garantía surge de su propia naturaleza como instrumento de defensa de los derechos humanos

\section{Clases}

Justino Jiménez de Aréchaga clasifica las garantías en genéricas y específicas. ${ }^{3}$ Las específicas refieren a determinado derecho, por ejemplo y en lo que a este estudio importa, el habeas corpus y el habeas data. Las garantías genéricas son de todos los derechos, por ejemplo, el amparo. ${ }^{4}$

Otros ejemplos son la necesidad de ley en sentido orgánico formal para regular los derechos reconocidos en la Constitución, la regulación del poder de emergencia como suspensión de la seguridad individual, etcétera.

3 Jiménez de Aréchaga, Justino, La Constitución Nacional, Montevideo, Edición del Senado Nacional Oriental, 1991, t. 1, p. 211.

4 Flores Dapkevicius, Rubén, Amparo, habeas corpus y habeas data, Buenos Aires, 2004, p. 151. 


\section{LOS PODERES DE EMERGENCIA}

\section{Concepto de poderes emergencia}

El orden jurídico garantiza la libertad y los derechos humanos con ese orden jurídico del Estado. Esa es una de las características del Estado de derecho material personalista. Sin embargo, pueden existir circunstancias excepcionales que ese orden no puede resolver. Por ejemplo inundaciones, crisis económicas, de abastecimiento de alimentos, sanitarias, guerras internas o externas. En tales supuestos, simplemente enumerados, se hacen necesarias medidas extraordinarias, reguladas de manera correcta por el derecho objetivo prexistente. Esas medidas podrán ser adoptadas por los funcionarios públicos de turno, entiéndase soportes del Poder Ejecutivo, dentro de los supuestos de hechos motivantes, para consolidar y proteger el Estado de derecho contra las agresiones o circunstancias que puedan atentar contra el mismo. Son los estados de emergencia. El derecho, general y lógicamente, establece soluciones para situaciones normales, donde el ataque al orden jurídico es de una intensidad razonable. Por ello, tratándose de circunstancias excepcionales deben arbitrarse soluciones excepcionales que garanticen el orden constitucional, pero regladas previamente para que no degeneren o motiven un golpe de Estado, persecuciones a determinadas personas, etcétera. ${ }^{5}$ Estos poderes excepcionales nacen visiblemente al mundo jurídico en el derecho romano con la consagración del instituto de la dictadura donde, por un plazo breve y en circunstancias extremas, el Senado otorga todos los poderes a un ciudadano romano para que lograra conservar el orden y la República.

Los poderes de emergencia, entonces, son los instrumentos reglados por el Estado de derecho para resolver esos conflictos extremos donde peligra la estabilidad y supervivencia del orden constitucional. Esa es su ratio legis, su razón de existencia y fin.

5 Ejemplo clásico de poder de emergencia se produce cuando el Parlamento aprobó en 1919 las leyes Rowlatt, que daban a las autoridades coloniales británicas poderes de emergencia para hacer frente a las actividades independendistas de la colonias. En Uruguay se tomaron medidas prontas de seguridad para garantizar el bien común en las trágicas inundaciones de 1959 y en el supuesto de la lucha del Poder Ejecutivo contra el Movimiento Tupamaro. La incorrección y abuso, en este último caso, del Poder Ejecutivo fue manifiesta porque el Parlamento levantaba las medidas y aquel Poder las restablecía aduciendo supuestos motivos similares: los mismos 
No son una dispensa de la Constitución, ruptura o derogación de la misma en un caso concreto o en un breve periodo (Verfassungsdurchbrechung), dejando inmutable su validez en general. ${ }^{6}$ Los poderes de emergencia reafirman el orden institucional y la vigencia plena de la Constitución con las particularidades del caso concreto y del poder de emergencia movilizado.

De principio es la Constitución, ${ }^{7}$ por su firmeza, valor y fuerza normativa y por provenir del pueblo quien los instituye, en forma taxativa en los supuestos autorizantes (motivos) aunque necesariamente en su regulación existan conceptos jurídicos determinables. ${ }^{8}$

Los estados de emergencia autorizan el ejercicio del poder de emergencia que se materializa mediante actos y hechos materiales. Esta distinción es trascendente. En la República Oriental del Uruguay se regulan y denominan suspensión de la seguridad individual y medidas prontas de seguridad. Sin embargo, existen diversos poderes en el derecho comparado con nomen juris diferentes, aunque todos, obviamente, tienen ese carácter excepcional. A vía de ejemplo recuérdese el estado de sitio del derecho napoleónico, estado de emergencia, ley marcial, etcétera.

Veamos algunos ejemplos. El artículo 27 de la Convención de San José de Costa Rica dispone:

Suspensión de garantías. 1. En caso de guerra, de peligro público o de otra emergencia que amenace la independencia o seguridad del Estado parte, éste podrá adoptar disposiciones que, en la medida y por el tiempo estrictamente limitados a las exigencias de la situación, suspendan las obligaciones contraídas en virtud de esta Convención, siempre que tales disposiciones no sean incompatibles con las demás obligaciones que les impone el derecho interna-

6 Biscaretti di Ruffia, Paolo, Derecho constitucional, Madrid, Tecnos, 1973, p. 274.

7 Aunque el legislador dicte leyes en aplicación de la carta magna. Así, España dictó la Ley Orgánica núm. 4/1981 y Portugal la Ley 44/86, disponibles en rflores@montevideo.com.uy.

8 Por ejemplo, "conmoción”, "grave crisis", “traición”, son conceptos que el funcionario que adopte el poder de emergencia deberá determinar, en forma razonable, para el supuesto de hecho motivante y concreto. Pongamos un caso: ¿existirá conmoción o grave crisis institucional, si existe acaparamiento de artículos de primera necesidad o si el pueblo, en estado de necesidad, efectúa saqueos a los supermercados? El concepto jurídico determinable deberá ser efectuado en cada caso concreto. Preferimos decir "concepto juridico determinable", porque es más preciso denotando la posible determinación, respecto a concepto jurídico "indeterminado". 
cional y no entrañen discriminación alguna fundada en motivos de raza, color, sexo, idioma, religión u origen social.

2. La disposición precedente no autoriza la suspensión de los derechos determinados en los siguientes artículos: $3 \mathrm{o}$. (derecho al reconocimiento de la personalidad jurídica); 4o. (derecho a la vida); 5o. (derecho a la integridad personal); 6o. (prohibición de la esclavitud y servidumbre); 9o. (principio de legalidad y de retroactividad); 12 (libertad de conciencia y de religión); 17 (protección a la familia); 18 (derecho al nombre); 19 (derechos del niño); 20 (derecho a la nacionalidad), y 23 (derechos políticos), ni de las garantías judiciales indispensables para la protección de tales derechos.

3. Todo Estado parte que haga uso del derecho de suspensión deberá informar inmediatamente a los demás Estados partes en la presente Convención, por conducto del secretario general de la Organización de los Estados Americanos, de las disposiciones cuya aplicación haya suspendido, de los motivos que hayan suscitado la suspensión y de la fecha en que haya dado por terminada tal suspensión. ${ }^{9}$

Por su parte, el artículo 23 de la Constitución de la Nación Argentina dispone:

En caso de conmoción interior o de ataque exterior que pongan en peligro el ejercicio de esta Constitución y de las autoridades creadas por ella, se declarará en estado de sitio la provincia o territorio en donde exista la perturbación del orden, quedando suspensas allí las garantías constitucionales. Pero durante esta suspensión no podrá el presidente de la República condenar por sí ni aplicar penas. Su poder se limitará en tal caso respecto de las personas, a arrestarlas o trasladarlas de un punto a otro de la nación, si ellas no prefiriesen salir fuera del territorio argentino. ${ }^{10}$

\section{Caracteres del ejercicio de los poderes de emergencia}

De acuerdo con lo expuesto en el apartado precedente surgen los siguientes tópicos.

9 La transcripción importa para observar cómo se establecen los límites precisos de las medidas en cuanto al objeto y el tiempo de duración de las mismas. Considérese, de todas formas, los conceptos jurídicos determinables analizados en la nota anterior.

10 El autor no puede y no debe transcribir, en este momento, cada poder de emergencia de los diversos países Considérese por ejemplo el artículo 16 de la Constitución de Francia de 1958; el artículo 180 de la Constitución del Ecuador de 1998; el artículo 111 de la Constitución de Bolivia de 1995, etcétera. 


\section{A. Excepcionalidad, taxatividad y brevedad}

Los poderes de emergencia son una excepción al orden jurídico normal. Esto significa que, en determinados supuestos, el órgano competente podrá adoptar una solución excepcional para defender el Estado de derecho y su orden jurídico. Y nada más. Toda solución que persiga otro fin está corrompida por desviación de poder.

Por lo expuesto y en general, de acuerdo con su naturaleza son, entonces, de breve duración y se extinguen cuando cumplen con el fin autorizado de antemano por el orden jurídico. Esa extinción, generalmente, es automática.

Su excepcionalidad determina, y esto es muy importante, su imposibilidad de extensión analógica y su interpretación estricta. Los supuestos de hecho autorizantes, motivos, son los determinados por la norma, taxatividad, no otros, ni circunstancias que el magistrado, funcionario público de turno, entienda de acuerdo a su conveniencia.

\section{B. No son regla de derecho}

Los poderes de emergencia, de principio, no modifican el orden jurídico. Al contrario, lo consolidan. No derogan la Constitución, ley o reglamento.

Cuando una persona que participa de una reunión es arrestada, en aplicación de una medida pronta de seguridad, no se está modificando o derogando el derecho de todo habitante de reunirse o asociarse. Simplemente se debería estar actuando para asegurar la seguridad pública y el Estado de derecho.

Lo expuesto es para el régimen Uruguayo que define la regla de derecho en el artículo 23 del Decreto Ley 15524 como todo principio de derecho o norma constitucional, legislativa reglamentaria o contractual. Para nosotros, los actos que emanan de los poderes de emergencia no son, de principio, reglamentos, de acuerdo con la clasificación del Decreto 500/91. Teniendo en cuenta los supuestos de hecho motivantes podrían ingresar en las restantes categorías legisladas en el artículo 120 del referido decreto. ${ }^{11}$ 


\section{Control}

Como mera introducción, ya que el tema será analizado más adelante, corresponde decir que los poderes de emergencia no son un cheque en blanco para utilizarlos de la forma que le plazca al funcionario de turno. Son medidas que tienen diversos controles tanto parlamentarios como jurisdiccionales. ${ }^{12}$

\section{LOS PODERES DE EMERGENCIA EN URUGUAY}

\section{La suspensión de la seguridad individual}

\section{El artículo 31 de la Constitución establece:}

La seguridad individual no podrá suspenderse sino con la anuencia de la Asamblea General, o estando ésta disuelta o en receso, de la Comisión Permanente, y en el caso extraordinario de traición o conspiración contra la patria; y entonces sólo para la aprehensión de los delincuentes, sin perjuicio de lo dispuesto en el inciso 17 del artículo 168.

Respecto a esta disposición corresponde decir:

\section{A. Seguridad individual}

Por seguridad, en general se entiende la situación de exención de peligro o daño. ${ }^{13}$ La seguridad individual,,${ }^{14}$ que es la que se suspende, se re-

dice: "Llámase Reglamento, a las normas generales y abstractas creadas por acto administrativo. Llámase Resolución, a las normas particulares y concretas creadas por acto administrativo. Llámase Disposición General, a las normas generales y concretas creadas por acto administrativo. Llámase Reglamento Singular, a las normas particulares y abstractas creadas por acto administrativo". El Decreto regula el procedimiento administrativo común y el disciplinario.

12 Flores Dapkevicius, Rubén, Amparo, habeas corpus y habeas data, Buenos Aires, B de F Editores, 2004, p. 152.

13 Ossorio, Manuel, Diccionario de ciencias jurídicas, políticas y sociales, Buenos Aires, Heliasta, 1997, p. 906.

14 La seguridad individual es una especie del género derecho a la o de seguridad. Para los uruguayos ese derecho es prexistente a la Constitución y ésta sólo establece su protección del goce, artículo 7 o. 
fiere esencialmente a las garantías que protegen a la persona, en especial la libertad física, la inviolabilidad de la correspondencia y del domicilio, artículos $11,15,17,28$ y 37 de la carta magna.

\section{B. Causales: traición y conspiración contra la patria ${ }^{15}$}

Las causales son diferentes a las establecidas para el supuesto que habilita a las medidas prontas de seguridad y que veremos a continuación. La suspensión sólo puede decretarse cuando se atenta, de una manera grave, contra la integridad del Estado, de la patria, o su soberanía nacional. Como se dijo, son conceptos determinables en cada caso. La traición es una violación de los ciudadanos a la fidelidad que se debe tener con la patria. Se visualiza fácilmente en el supuesto militar, en la entrega de secretos de Estado a un posible enemigo, etcétera. Las formas de traición son tan variadas como la casuística $\mathrm{y}$, ahora más que nunca, con la revolución informática.

Conspiración contra la patria es obrar contra la misma de consuno con el enemigo. La expresión "enemigo" es ambigua y determinable. Podrá ser enemigo el país que intenta una invasión, el que desea obtener fórmulas secretas, el que desea conocer cómo se puede violar la seguridad de nuestras reservas de oro depositadas en un fuerte, etcétera.

\section{Anuencia de la Asamblea General o de la Comision Permanente}

En este supuesto, a diferencia de las medidas prontas de seguridad, nos encontramos frente a una autorización del Poder Legislativo. Ello es así porque, también a diferencia de las medidas prontas de seguridad que son medidas esencialmente concretas, ${ }^{16}$ en la suspensión de la seguridad individual la situación es, de principio de carácter general refiriéndose a una categoría de personas (por ejemplo, los miembros de determinado pelotón), aunque pueda reglar situaciones de hecho concretas. La anuencia se expide mediante un acto administrativo porque no se debe seguir el procedimiento de sanción de las leyes. Ello es indubitablemente así porque la Comisión Permanente del Poder Legislativo actúa en los recesos parlamentarios o si se disuelve el Parlamento, no legisla

16 En tanto son "medidas" prontas de seguridad. 


\section{Autoriza sólo a la aprehensión de los delicuentes}

El instituto autoriza a los órganos encargados de velar por la soberanía nacional y seguridad pública, esto es principalmente el Poder Ejecutivo a arrestar a los delincuentes sin que rijan las garantías para el arresto establecido en los artículos 11y 15 de la Constitución de la Nación. Por lo expuesto se permite la aprehensión aunque no exista delito in fraganti $\mathrm{u}$ orden escrita del juez competente. También podrá realizarse esa aprehensión allanándose un domicilio en la noche. Obsérvese la gravedad y excepcionalidad autorizada motivada, exclusivamente, en las causales autorizantes.

\section{E. Procedencia de las garantías}

En nuestra opinión, si bien las garantías de los derechos humanos que surgen de la especie de que se trata, esto es seguridad individual, se encuentran limitadas, no se encuentran absolutamente eliminadas. Es decir que, en todo caso, podrán procesarse si se viola el artículo 31 de la Constitución que sólo autoriza la aprehensión de los "delincuentes". Si nos encontramos con una persona que manifiestamente no es un delincuente, existen desapariciones forzadas, etcétera, no cabe duda alguna que el habeas corpus, ${ }^{17}$ derecho subjetivo perfecto, esto es, no limitable, procede.

\section{Las medidas prontas de seguridad}

El artículo 168 de la Constitución uruguaya ${ }^{18}$ dice:

Al presidente de la República, actuando con el ministro o ministros respectivos, o con el Consejo de Ministros, corresponde: 17) Tomar medidas prontas de seguridad en los casos graves e imprevistos de ataque exterior o conmoción interior, dando cuenta, dentro de las veinticuatro horas a la Asamblea General, en reunión de ambas cámaras o, en su caso, a la Comisión Permanente, de lo ejecutado y sus motivos, estándose a lo que estas últimas resuelvan.

En cuanto a las personas, las medidas prontas de seguridad sólo autorizan a arrestarlas o trasladarlas de un punto a otro del territorio, siempre que no optasen

17 Flores Dapkevicius, Rubén, op. cit., nota 12, p. 152.

18 Flores Dapkevicius, Rubén, Constitución de la República Oriental del Uruguay de 1967, anotada y concordada, Montevideo, Amalio Fernández, 2004, nota al artículo 168. 
por salir de él. También esta medida, como las otras, deberá someterse, dentro de las veinticuatro horas de adoptada, a la Asamblea General en reunión de ambas cámaras $\mathrm{o}$, en su caso, a la Comisión Permanente, estándose a su resolución.

El arresto no podrá efectuarse en locales destinados a la reclusión de delincuentes.

\section{Causales:}

a. Casos graves e imprevistos de ataque exterior

Ataque exterior es, razonable y generalmente, invasión armada al territorio nacional. Sin embargo, también, puede considerarse en esta causal otras circunstancias que preparen una situación que pueda atentar contra el Estado de derecho, o una futura invasión, por ejemplo, el espionaje militar. Ese ataque debe ser grave, es decir, no puede ser cualquier tipo de agresión. Además, imprevisto. Esa imposibilidad de previsión debe considerarse de una forma razonable.

Debe destacarse que, obviamente, para que el instituto sea efectivo, el supuesto se extiende a la inminencia de un ataque exterior.

\section{b. Conmoción interior}

La conmoción interior, o su inminencia, puede ser política, económica, motivada por razones sanitarias, climatológicas, etcétera. Sin embargo el concepto debe entenderse sin que se desnaturalice la ratio legis del instituto.

Esos conceptos jurídicos determinables deberán determinarse, con precisión, de acuerdo al supuesto de hecho del caso en su momento histórico.

\section{Comunicación a la Asamblea General o Comisión Permanente dentro de las veinticuatro horas}

En este supuesto, a diferencia de la suspensión de la seguridad individual, nos encontramos con un acto de aprobación, a posteriori, que comunica generalmente las "medidas" prontas de seguridad que son concretas. 


\section{El órgano legislativo es el que decide}

Se está en presencia de una comunicación a posteriori, aunque en todo caso debe estarse a lo que el órgano legislativo competente decida. Esa decisión debe ser respetada formal y, sustancialmente, por el Poder Ejecutivo, que no puede burlar la Constitución mediante la adopción de nuevas medidas por hechos similares o disfrazados para que parezcan diferentes. En todos estos supuestos debe prevalecer la razonabilidad y la defensa del Estado de derecho, no política coyuntural.

La Asamblea General puede adoptar tres actitudes.

c) No se reúne o, habiéndose efectuado la reunión, no decide. En ese caso las medidas continúan vigentes.

d) Aprobar las medidas.

e) Levantarlas y, en ese caso, el Poder Ejecutivo no las puede continuar y debe dejar sin efecto las ya adoptadas.

La decisión del cuerpo legislativo se materializa mediante un acto administrativo porque no se necesita ley a los efectos de que se trata. ${ }^{19}$

\section{Autoriza sólo la aprehensión o traslado}

En el supuesto de las medidas prontas de seguridad no nos encontramos, necesariamente, frente a delincuentes como en el supuesto de la suspensión de la seguridad individual. Por ello, la norma es sumamente cuidadosa y permite la opción de salir del país. En el supuesto de la suspensión de la seguridad individual la situación es diversa en el sentido que nos encontramos, de principio, con personas que cometieron o están a punto de cometer un delito contra la patria.

Asimismo, encontrándonos en supuestos donde el arrestado no es un delincuente, no puede recluírselo con los mismos. De lo expuesto observamos que las medidas prontas de seguridad son medidas particulares (por ejemplo, se arresta a una persona determinada), no son reglas generales, ni se refieren, de principio, a una situación general, como en el supuesto de la suspensión de la seguridad individual.

19 Flores Dapkevicius, Rubén, Manual de derecho público, Buenos Aires, Euros Editores, 2007, t. II, p. 345. 


\section{Procedencia de las garantías}

No existe duda que todas las garantías de los derechos humanos son procedentes para controlar la adopción correcta de éste y todos los poderes de emergencia, como se dijo para la suspensión de la seguridad individual.

\section{CONTROL DE LOS PODERES DE EMERGENCIA}

Lo que interesa en este apartado es que los poderes de emergencia, analizados antes, tienen un régimen jurídico propio, esto es, tienen el valor y fuerza que emana del ejercicio de la función administrativa, con algunas particularidades que surgen de su propia naturaleza,

Tanto la suspensión de la seguridad individual como las medidas prontas de seguridad, conllevan idéntica pretensión: restablecer el orden público alterado y la plena vigencia de la Constitución. Para lograrlo, entre otros efectos, restringen las libertades y garantías establecidas en ésta. Es menester interpretar las normas de derecho que los instituyen con criterio limitativo y no extensivo; todo en defensa de la libertad. ${ }^{20}$

Por lo expuesto, a juicio de quien dice, las medidas prontas de seguridad serían procesables ante el Tribunal de lo Contencioso Administrativo, que es competente en la acción de nulidad de los actos administrativos definitivos.

En efecto, no surge del artículo 168 ord. 17 ni del artículo 309 de la carta magna, ${ }^{21}$ que la Asamblea General o la Comisión Permanente, en su caso, tengan competencia exclusiva para controlar la legalidad de esos actos y los que emanen de su aplicación.

El Tribunal de lo Contencioso Administrativo se ha declarado competente respecto de actos administrativos dictados en aplicación de medidas de seguridad de contenido genérico porque no puede suponerse el aval tácito del Parlamento en favor de todos los actos que sobrevengan como consecuencia del decreto (sentencias 40 y 163 de 1974).

20 Semino, Miguel Ángel, "La suspensión de la seguridad individual en el derecho constitucional uruguayo", R. D. J. A. T., núm. 69, p. 164.

21 Flores Dapkevicius, Rubén, op. cit., nota 18, nota al artículo 168. 
Si se sostiene la eventual inmunidad contencioso anulatoria de las medidas prontas de seguridad, ello no impide que la persona afectada pueda reclamar la indemnización patrimonial de los perjuicios ocasionados por las mismas (sentencia 68/975). ${ }^{22}$

A similar solución puede arribarse, según la casuística respecto de las medidas que se adopten en relación con la suspensión de la seguridad individual. ${ }^{23}$

En lo que se refiere al ejercicio de las garantías constitucionales, esto es, el amparo, habeas corpus y habeas data, serán procesables de acuerdo con la situación concreta. Por ejemplo, y en todo caso, podrá procesarse el habeas corpus si se viola el artículo 31 de la carta magna que sólo autoriza la aprehensión de los "delincuentes". También procederá si en el supuesto de las medidas prontas de seguridad no se otorga la opción de salir fuera del país o el detenido lo es en lugar donde se encuentran delincuentes. ${ }^{24}$ Se reitera, los poderes de emergencia no son un cheque en blanco. ${ }^{25}$

\section{LOS PODERES DE EMERGENCIA INTEGRAN EL ORDEN JURÍDICO. LOS ACTOS EN SU EJERCICIO NO SON REGLA DE DERECHO}

En Uruguay es clara la distinción. Por una parte tenemos los hechos motivantes de la emergencia, lo que nosotros entendemos como estados de emergencia. Ellos serán las causas para iniciar la secuencia que determine adoptar medidas prontas de seguridad o suspender la seguridad individual, por ejemplo traición o conspiración contra la patria. Situación diversa es el poder de emergencia reglado en la Constitución, esto es, la suspensión de

22 Obsérvese que todas las sentencias son concomitantes o posteriores a 1973 (golpe de estado en la República Oriental del Uruguay) periodo en que se aplicó reiteradamente el poder de emergencia.

23 En todo caso debe considerarse si el acto administrativo no ingresa en la categoría de acto de gobierno reconocido en nuestra legislación, Decreto Ley 15524, artículo 26.

24 Gros Espiell, Héctor, "Habeas corpus", El poder y su control, Montevideo, UCUDAL, 1994, pp. 140 y ss., expresa que de acuerdo con el artículo 7o. de la Convención Americana sobre Derechos Humanos existe el habeas corpus que deriva de la Convención. "Ahora una decisión gubernamental que dijera que el habeas corpus no existe bajo... medidas prontas de seguridad... constituiría una violación del gobierno uruguayo... a la referida Convención".

25 Flores Dapkevicius, Rubén, op cit., nota 12, p. 233. 
la seguridad individual y las medidas prontas de seguridad. Por último, para dictar los actos administrativos necesarios para el ejercicio del poder debe seguirse una secuencia procedimental

\section{CONCLUSIONES}

1. Estado de derecho material personalista es aquel orden jurídico que se caracteriza por la democracia, la sujeción del Estado y su administración a la ley y el respeto de los derechos subjetivos de los individuos que son prevalentes al poder público siempre y especialmente en el supuesto de duda.

2. Los derechos humanos son el conjunto de derechos de que gozan las personas y que no pueden ser restringidos ni violados, esencialmente, por los gobernantes. Los poderes de emergencia no son un cheque en blanco a esos efectos.

3. Las garantías de los derechos humanos son los instrumentos que materializan y consolidan los derechos del hombre. Se desarrollan, esencialmente, en instrumentos del derecho constitucional procesal.

4. Los poderes de emergencia son los instrumentos reglados por el Estado de derecho para resolver conflictos extremos donde peligra la estabilidad y supervivencia del orden constitucional.

5. El ejercicio de los poderes de emergencia se caracterizan por su excepcionalidad, interpretación estricta sin posibilidad de analogía ni constituir reglas de derecho y por su posible control legislativo y jurisdiccional.

6. Debe distinguirse el poder de emergencia del estado de emergencia, que motive la movilización del referido poder mediante la secuencia procedimental que dará lugar a la dictación de los actos administrativos, necesarios para conservar el orden jurídico soporte del Estado de derecho material personalista.

7. Los poderes de emergencia son controlables, de acuerdo con la reglamentación constitucional correspondiente, por el Parlamento y el Poder Judicial. Éste debe dar trámite a las garantías que se presenten y observar la regularidad constitucional de las medidas que se adopten en los estados de excepción

8. Es necesario que el orden jurídico establezca los poderes de emergencia para la protección del Estado de derecho material personalista, en 
el supuesto de circunstancias extremas que hagan peligrar la regularidad constitucional

9. Esos poderes, que en primer lugar deben estar consagrados en la Constitución, deben autorizar medidas taxativas en situaciones taxativas. La regulación del detalle es una garantía absolutamente necesaria. La redacción debe ser extremadamente cuidadosa y prescindir, dentro de lo posible, de diversas interpretaciones, eliminando los conceptos jurídicos determinables de su redacción.

10. El poder que otorga el poder de emergencia debe limitarse a los efectos de que no desemboque en un golpe de estado u otros abusos del Poder Ejecutivo respecto de bienes y derechos humanos de personas determinadas. $^{26}$

\section{BIBLIOGRAFÍA}

ARAGÓN, Manuel, Constitución y control del poder, Ed. Ciudad Argentina, 1996.

BISCARETTI DI RUFFIA, Paolo, Derecho constitucional, Madrid, Tecnos, 1973.

Dromi, Roberto, Derecho administrativo, Buenos Aires, 1997.

FIX-ZAMUdio, Héctor, Juicio de amparo, México, Porrúa, 1964.

FLORES DAPKEVICIUS, Rubén, Manual de derecho público, Buenos Aires, Euros Editores, 2007, 2 ts.

- Amparo, habeas corpus, habeas data, Buenos Aires, Editorial B de F, 2004.

—_, Constitución de la República Oriental del Uruguay, anotada y concordada, Montevideo, Amalio Fernández 2004.

GONZÁlez CALDERÓN, Juan A., Curso de derecho constitucional, Buenos Aires, 1943.

GordiLlo, Agustín A., Tratado de derecho administrativo, Buenos Aires, Macchi, 1975.

GROS ESPIELL, Héctor, Habeas corpus, en el poder y su control, Montevideo, UCUDAL, 1994.

JiMÉNEZ DE ARÉCHAGA, Justino, La Constitución Nacional, Montevideo, Cámara de Senadores, 1998. 
LABAURE ALISERIS, Carlos, "Estado social: del intervensionismo a la subsidiariedad", Anuario de Derecho Administrativo, Montevideo, FCU, 1999, t. VII.

MARIENHOFF, Miguel, Tratado derecho administrativo, Buenos Aires Abeledo Perrot, 1975.

MORELl OCAÑA, Luis, Curso de derecho administrativo, España, Aranzadi, 1999.

Rotondo, Felipe, Manual de derecho administrativo, Montevideo, Del Foro, 2000.

SAGÜÉS, NÉSTOR, Pedro, Habeas Corpus Ley 23098 comentada y concordada, Buenos Aires, Astrea, 1988.

SEMINO, Miguel, "El control de las medidas prontas de seguridad", Revista de Derecho Público, Montevideo, núm. 1, 1973.

TOFFLER, Alvin, El cambio del poder, España, Plaza \& Janes, 1994.

VANOSSI, Jorge, Teoría constitucional, Montevideo, Buenos Aires, Depalma, 1975. 